\title{
Indicativos de uma aritmética para ensinar na formação de professores em um curso de férias na Bahia
}

\author{
Indicative of an arithmetic to teach in the formation of teachers in a \\ course of vacations in Bahia
}

\author{
Cézar Jesus da Rocha ${ }^{1}$ \\ Moysés Gonçalves Siqueira Filho²
}

\section{Resumo}

Tem por objetivo identificar características de uma aritmética para ensinar na Bahia, por meio das orientações para o ensino de aritmética nos cursos de férias, ocorridos em 1927 e 1928, voltados para a formação dos professores primários e instituídos pela Lei 1.846, de 14 de agosto de 1925, que dispõe sobre a Reforma da Instrução Pública no Estado. Para tanto, [1] identifica os experts que estiveram junto de Anísio na elaboração e/ou divulgação de uma aritmética para ensinar; [2] inventaria, em documentos relativos à formação de professores, as orientações para o ensino de aritmética, apresentada pelos experts nas conferências do Curso de Férias. Trata-se de uma pesquisa qualitativa, de cunho histórico-documental fundamentada por alguns conceitos da História Cultural, tais como: representação e apropriação, propostos por Roger Chartier, e estratégias, apresentado por Michel De Certeau. Sinaliza a articulação de diferentes conteúdos, saberes pedagógicos e métodos de ensino na constituição de uma aritmética para ensinar na Bahia. Identifica que o tripé da aritmética para ensinar consistia na capacidade do professor em tornar o ensino concreto, prático e lúdico, além de favorecer possibilidades de descobertas e interconexões entre os saberes aritméticos escolares e as situações da vida prática, em que eles eram necessários.

Palavras chave: aritmética; formação de professores; Bahia.

\section{Abstract}

It aims to identify characteristics of an arithmetic to teach in Bahia, through the guidelines for the teaching of arithmetic in the vacations courses, occurred in 1927 and 1928, aimed at the training of primary teachers and instituted by Law 1,846, August 14 of 1925, which provides for the Reform of Public Instruction in the State. To do so, [1] identifies the experts who were with Anísio in the elaboration and/or dissemination of an arithmetic to teach; [2] he would invent, in documents related to teacher training, the guidelines for the teaching of arithmetic, presented by the experts in the conferences of the Holiday Course. It is a qualitative, historical-documentary research based on some concepts of Cultural History, such as: representation and appropriation, proposed by Roger Chartier, and strategies, presented by Michel De Certeau. It indicates the articulation of different contents, pedagogical knowledge and teaching methods in the constitution of an arithmetic to teach in Bahia. He identifies that the tripod of arithmetic to teach consisted of the teacher's ability to make teaching concrete, practical and playful, as well as favoring possibilities for discoveries and interconnections between the arithmetic scholarly knowledge and practical life situations in which they were needed.

Keywords: arithmetic; teacher training; Bahia.

\footnotetext{
${ }^{1}$ Universidade Federal do Espírito Santo | cezarjrocha@hotmail.com

2 Universidade Federal do Espírito Santo | siqueira.moyses@gmail.com
} 


\title{
Introdução
}

O recorte da pesquisa que por ora apresentamos, busca identificar características de uma aritmética para ensinar na Bahia, por meio das orientações para o ensino de aritmética nos cursos de férias ocorridos em 1927 e 1928, voltados para a formação dos professores primários e instituídos pela Lei 1.846, de 14 de agosto de 1925, que dispõe sobre a Reforma da Instrução Pública no Estado.

Esse período situa-se em um momento de transição entre as ideias advindas da Pedagogia Moderna e o florescimento do movimento da Escola Nova, fato que merece um olhar especial, no intuito de verificar as continuidades e/ou descontinuidades presentes na formação de professores voltada à uma aritmética para ensinar na Bahia.

Por meio da reforma de 1925, Anísio Teixeira que, à época, era diretor Geral da Instrução Pública no estado, começou a disseminar na educação baiana ideias que, mais tarde, estariam presentes no Manifesto dos Pioneiros da Educação Nova. Sabemos que, após conhecer o modelo de ensino norte-americano, ele se tornou um grande propagador dessas ideias pedagógicas, defendendo um modelo de educação em que o aluno deveria ser o centro do processo educativo, a partir da experimentação, da observação e do aprender por meio da ação.

\begin{abstract}
A Escola Nova, inspirada em grande medida nos avanços do movimento educacional norte-americano, mas também de outros países europeus, teve grande repercussão no Brasil. Os ideais que Ihe deram corpo foram sempre inspirados na concepção de aprendizado do aluno por si mesmo, por sua capacidade de observação, de experimentação, tudo isso orientado e estimulado por profissionais da educação que deveriam ser treinados especialmente para esse fim [...] (BOMENY, 2003, p. 43).
\end{abstract}

Note-se que havia uma concepção de aprendizagem que prezava pelo protagonismo dos alunos na significação dos saberes, sem abrir mão, no entanto, de questões relacionadas ao ensino. De modo especial, existia uma preocupação com a formação docente. Nesse sentido, este artigo propõe refletir sobre como a aritmética para ensinar foi caracterizada pelos professores escolhidos por Anísio Teixeira, para as formações ofertadas nos cursos de férias.

Para tanto, a partir de uma abordagem qualitativa de cunho histórico-documental debruçamo-nos sobre as palestras proferidas nos cursos de férias com vista ao entendimento das orientações para o ensino dos saberes aritméticos naquele momento, tendo o cuidado em analisá-los e questioná-los, considerando a época, o lugar e os contextos políticos, sociais e econômicos em que estiveram submetidos, bem como, os processos de transformação ocorridos na sociedade desde então.

Por compreender que o conhecimento não pode ser analisado desconsiderando a cultura na qual ele esteve inserido e foi produzido, buscamos na história cultural conceitos que ajudam esclarecer as práticas do passado, considerando o contexto em que ocorreram. Para tanto, recorremos aos conceitos de representação e apropriação propostos por Roger Chartier, e de estratégias, apresentado por Michel De Certeau.

Chartier (1990) nos alerta para o fato de que a trajetória histórica de significação e constituição de determinados saberes está ligada a fatores sociais, institucionais e culturais e não pode ser considerada como uma construção linear. Ainda, segundo esse autor, a história configura-se como um instrumento capaz de reconstituir, por meio do discurso 
social, formas de representação das realidades do passado a partir das contradições e congruências dos agentes de determinado contexto. Reconstituir a história é "submeter à experimentação crítica os modelos forjados em outros contextos" (CHARTIER, 2002, p. 152).

Nessa perspectiva, a história cultural é entendida como uma operação historiográfica que busca estabelecer uma relação entre o real e o discurso na construção de uma narrativa histórica. Por meio de questionamentos às fontes, contribui para uma leitura da realidade em conformidade com as características que os diferentes lugares e momentos teceram-na.

Entretanto, tendo em vista que não é possível reviver os diferentes lugares e momentos históricos para, assim, proceder a identificação e releitura da realidade vivida, ou seja, suas representações, torna-se relevante para a construção do processo historiográfico, admitir

[...] um dos conceitos mais importantes utilizados pelos homens do Antigo Regime, quando pretendem compreender o funcionamento da sua sociedade ou definir as operações intelectuais que Ihes permitem apreender o mundo. Há aí uma primeira e boa razão para fazer dessa noção a pedra angular de uma abordagem a nível (sic) da história cultural (CHATIER, 2002, p. 23).

Segundo o mesmo autor, a representação permite a articulação entre as práticas, utilizadas por determinados grupos para marcar visível e, perpetuamente, sua existência e realidade.

Por conseguinte, o conceito de apropriação emerge como mais um termo capital, pois, em um mesmo momento, as orientações oficiais são recebidas e adaptadas de maneiras diferentes pelos diversos sujeitos do processo, ou seja, incidem em diferentes apropriações. Para Chartier (2002, p. 26)

[...] a noção de apropriação pode ser, desde logo, reformulada e colocada no centro de uma abordagem de história cultural que se prende com práticas diferenciadas, com utilizações contrastadas [...] tal como entendemos, tem por objectivo uma história social das interpretações, remetidas para as suas determinações fundamentais (que são sociais, institucionais, culturais) e inscritas nas práticas especificas que as produzem.

Outro domínio, articulado por De Certeau (1994, p. 99), também, ganha singular relevância nesse artigo: estratégia. Esta configura-se pelo "[...] cálculo (ou a manipulação) das relações de forças que se torna possível a partir do momento em que um sujeito de querer e poder [...] pode ser isolado".

Entendemos, pois, que dialogar com os documentos, implica valorizá-los e interpretálos, porém, atentos para possíveis distâncias entre as recomendações oficiais, disseminadas por meio das estratégias dos legisladores e formadores, e o que se efetivou nas escolas por meio dos professores primários. Como nos afirma Faria Filho (2000), diversos significados ou interpretações podem advir de uma legislação.

Nesse sentido, o historiador precisa assumir, de acordo com Bloch (2001), uma postura crítica frente às mais diversas fontes documentais; compreender o fenômeno social, a partir do seu contexto histórico; contrapor as diferentes abordagens dadas ao tema pelos sujeitos 
envolvidos, ou seja, propõe colocar em dúvida os documentos, fazendo da análise crítica um caminho de veracidade ${ }^{3}$, além de instrumentalizar-se de outras áreas do conhecimento para fomento de sua pesquisa.

A partir dessas premissas, queremos compreender, ao menos em parte, os indicativos de uma aritmética para ensinar, promovida a partir da formação dada nos cursos de férias, uma estratégia utilizada pela Diretoria Geral da Instrução Pública da Bahia, cujo intuito fora o de disseminar as novas concepções sobre o ensino e as práticas pedagógicas que os professores deveriam adotar na escola primária.

Complementam, ainda, nosso referencial teórico, as noções de saberes a e para ensinar e sua intrínseca relação com os experts. No que se refere a esses saberes, Valente (2017) assinala que estudos feitos pela Equipe de Pesquisa em História das Ciências da Educação (ERHISE) da Universidade de Genebra na Suíça apontam que a constituição dos saberes para formação de professores de nível primário e secundário relacionam-se à compreensão de como se articulam dois tipos de saberes: os saberes para ensinar, ou seja, aqueles constitutivos do campo profissional (expertise profissional) e os saberes a ensinar, aqueles produzidos pelas disciplinas universitárias. Por desdobramento, compreendemos a aritmética para ensinar como sendo o conjunto de saberes constitutivos do campo profissional stricto do professor de aritmética, ou seja, expertises necessárias para o ensino desta disciplina.

Complementa a compreensão de tais saberes, o papel desempenhado pelos experts. Para Hofstetter et al. (2017), constituindo-se como especialistas que se distinguem pelos seus conhecimentos, atitudes, experiências, os experts participam da produção de saberes no campo pedagógico. Nessa perspectiva, a análise da constituição e institucionalização da expertise $e^{4}$ ajuda a perceber os movimentos de objetivação e institucionalização dos saberes a e para ensinar.

Entendemos que a análise referenciada nas categorias saberes a ensinar e saberes para ensinar amplia a compreensão do processo de constituição das disciplinas e dos saberes profissionais dos professores. Outrossim, a interdependência entre esses dois tipos de saberes possibilita outras perspectivas de reflexão, ao considerar, além dos fatores epistemológicos, as didáticas das matemáticas que, ao mesmo tempo em que transformam os saberes a ensinar, são transformadas por eles. Permite, ainda, refletir como os saberes a ensinar estiveram atrelados ao movimento de promoção, reconhecimento e constituição dos denominados saberes pedagógicos e didáticos que ajudam a compor os saberes do campo profissional.

\footnotetext{
${ }^{3}$ Não se quer dizer com isso, que esse caminho de veracidade seja a busca utópica de uma verdade absoluta por meio da história, ao contrário, trata-se de uma tentativa de compreender as práticas do passado à luz do seu contexto histórico.

${ }^{4}$ A noção de expertise é entendida como habilidades específicas de um ou vários especialistas, reconhecidas como legítimas, "[...] supostamente distinguidos pelos seus conhecimentos, atitudes, experiências -, a fim de examinar uma situação, de avaliar um fenômeno, de constatar fatos" (HOFSTETTER et al. 2017, p. 57).
} 


\section{A formação de professores na reforma da instrução pública baiana de 1925}

Assim que assume o cargo de Diretor Geral da Instrução Pública na Bahia, Anísio Teixeira propõe algumas mudanças no ensino baiano. Devido à falta de experiência no campo educacional, viaja para a Europa e depois para os Estados Unidos, onde, em 1927, faz cursos na Columbia University, conhece o Filósofo e Educador Jonh Dewey e visita várias escolas americanas para conhecer o modelo de ensino praticado. Sobre essa viagem, escreve um relatório que resultou na obra "Aspectos Americanos de Educação".

Sob sua direção, em 1925, foram promulgados, no âmbito da Administração Educacional da Bahia, a Lei no 1846, de 14 de agosto, (Reforma da Instrução Pública); o Programa de Ensino da Escola Elementar Urbana; e o Decreto n 4218, de 30 de dezembro, (Aprova o Regulamento do Ensino Primário e Normal). Esses documentos marcaram, positivamente, a passagem de Anísio Teixeira na Bahia, até porque, mesmo depois do seu pedido de demissão, ocorrido em 1929, tais documentos permaneceram vigentes, salvo pequenas legislações complementares, por vinte e dois anos. Somente em 1947, quando Anísio assume, novamente, o cargo, no governo de Otávio Mangabeira, é sugerido, por ele mesmo, a reestruturação dos referidos documentos.

Sant'Ana et al. (2015) enfatizam a preocupação de Anísio Teixeira com a qualidade do ensino e a formação dos professores primários, nas duas gestões junto à Secretária de Instrução Pública no estado da Bahia. No primeiro momento (1924-1929), buscou ampliar, para o interior do estado, os cursos de formação de professores e, no segundo (19471951), além de enviar professores baianos ao Rio de Janeiro, para cursos de especialização, dedicou-se à elaboração da Lei Orgânica de Ensino, na qual, a partir das ideias do movimento da Escola Nova, propôs a autonomia da Secretaria da Educação e a educação integral no ensino primário. No entanto, a Lei não foi aprovada e isso, de certo modo, revelou sua insatisfação e ocasionou um novo pedido de exoneração, em 1948, ato que não se concretizou devido ao pedido de sua permanência por parte do governador.

A Lei 1846, de 14 de agosto de 1925, para além da expansão do ensino, trouxe à tona as discussões educacionais em torno da renovação da educação. Ao apresentar o objetivo geral do ensino público do estado da Bahia, o artigo primeiro esclareceu que "educar physica, moral e intellectualmente o indivíduo, torna-[o] apto para a vida em sociedade" (BAHIA, 1925, p. 177).

Nessa perspectiva, algumas palavras-chave, como necessidade e interesse da criança, fizeram-se muito presentes nas discussões, pois esses elementos, associados à ação, eram vistos como desencadeadores para promover o desenvolvimento das potencialidades dos alunos, e os trabalhos manuais passaram a se constituir em um mecanismo privilegiado para potencializar esse tipo de ensino.

Embora a Lei 1846/25 apostasse na ação do aluno como elemento essencial para a aprendizagem, ideias próximas, advindas da Pedagogia Moderna, tais como o uso do método intuitivo e a valorização dos objetos concretos no ensino, já se faziam presentes no cenário educacional baiano desde o final do século XIX, mas somente por meio dessa legislação se potencializou, incorporou novas ideias do movimento da Escola Nova e passou a constituir as diretrizes que orientaram os currículos e programas, sendo fator decisivo para a escolha de manuais didáticos e publicações pedagógicas, além de referenciar os cursos de aperfeiçoamento de professores da escola primária. 
Na Bahia, segundo D'Esquivel (2015), o ensino intuitivo introduzido no final do século XIX ganha destaque na reforma do ensino de 1925, e os programas de ensino propostos e a formação inicial e continuada do professor passam a ter a preocupação com as formas de ensinar.

Ainda, segundo D'Esquivel (2015), o advento da República trouxe em seu seio a ordem imperativa de ampliação da oferta de instrução pública e isso implicou que novos currículos e programas fossem pensados de modo a permitir uma nova organização dos níveis de ensino e dos conteúdos. Começou a aparecer nas leis um detalhamento dos programas de ensino, agregando as matérias aos métodos pedagógicos e às formas de avaliação, algo que é perceptível na reforma proposta por Anísio Teixeira, em que os programas, tanto do Ensino Normal quanto do Ensino Primário, apresentam uma organização bem definida.

À vista disso, o Programa de Ensino e as formações ofertadas na Bahia, desde então, mostraram-se como espaço privilegiado para a disseminação de conhecimentos e se tornam objeto interessante para compreendermos a aritmética para ensinar, pois dão pistas da trajetória de constituição e ressignificação da aritmética a e para ensinar, bem como, as transformações no ideário pedagógico para o ensino primário e as orientações didáticas a partir de tais saberes.

\section{Cursos de férias: uma estratégia de formação ancorada nos novos ideais pedagógicos}

A formação do professor para atuar no ensino primário ficou estabelecida na Lei 1846/25 por meio de três modalidades: formação inicial na Escola Normal, "aperfeiçoamento pedagógico e literário" na Escola Normal Superior e uma espécie de formação continuada ${ }^{5}$ por meio dos chamados "Cursos de Férias" (BAHIA, 1925, p.207).

Destinados à formação continuada dos professores, os Cursos de Férias, também, tiveram toda a sua estrutura - objetivos, local, público alvo e, até mesmo, a data para sua realização determinada pela referida legislação. Deveriam ser realizados, todos os anos na Escola Normal da capital, entre os dias 1 e 20 de janeiro, e organizados em um programa especial pelo diretor geral da instrução pública. A proposta era a de que a cada cinco anos, todos os professores do estado dele participassem. O principal objetivo era:

[...] indicar a orientação moderna do ensino primario e procurar estabelecer de modo preciso a finalidade e a correlação que deve existir entre as diversas disciplinas, cogitando também dos assumptos que constituem interesse vital e progressista do ensino (BAHIA, 1925, p. 208).

Para tanto, seriam convidados lentes ${ }^{6}$ e professores das Escolas Normais ou de outros estabelecimentos de ensino, ou mesmo, pessoas de notório saber para ministrar conferências acompanhadas de demonstrações práticas, sempre que possível.

\footnotetext{
${ }^{5}$ A legislação não se utiliza do termo "formação continuada", mas, a partir das finalidades apresentadas, nos permite compreender que se tratou de uma proposta de formação permanente, em serviço, para os professores primários.

${ }^{6}$ Do termo latino legente, "que lê", era usado para designar o professor catedrático.
} 
A respeito desses cursos, Anísio Teixeira escreve que eles foram realizados com êxito nos anos de 1927 e 1928 e tratavam de "[...] cursos de modernização do ensino [...]" destinados a "facilitarem a adaptação do professorado às modernas e justas exigências de reforma da escola pública" (TEIXEIRA, 1928a, n.p.).

Segundo o mesmo relatório, a frequência em 1927, contou, apenas, com professores da capital, e seu programa se estruturou por meio de cinco eixos norteadores: [1] orientação moderna do ensino primário; [2] finalidade e correlação entre as suas diversas disciplinas; [3] orientação profissional pela escola; [4] saúde e higiene na escola e [5] pedologia.

As conferências ocorridas, nesse ano, nos fornecem, além de orientações sobre as concepções pretendidas quanto aos métodos de ensino, indicativos sobre as matemáticas a ensinar nas escolas primárias do estado. Dentre elas podemos citar: "A orientação moderna do ensino primário - A escola baiana", que se constitui na palestra de abertura, ministrada pelo próprio Anísio Teixeira; "O ensino de desenho na escola primária", ministrada pelo professor Arthur Mendes Aguiar; "O ensino de matemática na escola primária", ministrada pela professora Julia Leitão e; "Trabalhos manuais na escola primária", ministrada pela professora Alzira de Assis.

Vale salientar que, dos nomes acima citados, com exceção de Anísio Teixeira, os palestrantes eram professores ou diretores escolares, escolhidos pela Diretoria de Instrução Pública do Estado.

Em seu relatório, Anísio Teixeira escreve que:

O curso de férias, a tradução do livro de Omer Buyse e a constante propaganda dos trabalhos manuaes e do desenho na escola virão facilitar a execução dos actuaes programmas, que buscam, acima de tudo, approximar a escola da vida, para tornal-a mais efficiente e mais verdadeira (TEIXEIRA, 1928a, n.p.).

A modernização do ensino orientava-se pela legislação que reformou a instrução pública e pelos programas escolares. Mas foi a tríade relatada por Anísio Teixeira a grande responsável pela divulgação das ideias pedagógicas que impulsionaram a reforma e por fornecer orientações, sobretudo práticas, para o ensino.

De acordo com o relatório supracitado, o Curso de Férias repetiu-se em 1928 com igual, ou melhor êxito, no entanto, não contemplou conferências que tratassem do ensino de matemática. Participaram 311 professores, advindos de vários lugares da Bahia, apesar da ajuda de custo e transporte ao professorado do interior, prevista em lei, não ter ocorrido por motivo de problemas orçamentários.

No relatório intitulado "Educação e Saúde na Bahia", escrito por Isaías Alves, em 1939, constatamos que tais cursos, devido ao sucesso que tiveram, foram retomados e ampliados em outras gestões por serem vistos como uma oportunidade de intensificar o trabalho de renovação intelectual do professorado, de modo especial, dos professores do interior que passaram a vir à capital para receber essa formação.

Considerando as vantagens de seu trabalho intensivo, em que a inteligencia desperta e a consciencia se esclarece, foi resolvido realizaremse, com regularidade, todos os anos, cursos de férias, cujas despesas são sobejamente compensadas pelo otimismo que adquirem os professores, pelo entusiasmo e curiosidade intelectual que provocam novas leituras. Isso tem ficado evidente durante todo o movimento que se vem fazendo 
desde as conferências de 1938, pela aquisição, em maior escala, de livros de orientação geral e pedagógica (ALVES, 1939, p. 25).

Segundo Alves (1939), essas novas etapas de formação passaram a contar com professores formadores vindos de outros estados. No curso de 1938, por exemplo, foram convidados professores mineiros por intermédio do secretário de educação e saúde, o doutor Christiano Machado. Um dos formadores convidados foi a professora Alda Lodi, da Escola de Aperfeiçoamento de Belo Horizonte.

No curso de 1939 foram abertas 200 inscrições, mas, devido à grande procura, a oferta fora ampliada, e dele participaram 308 professores, recebendo, cada um, formação de acordo com a sua área de atuação.

Anísio Teixeira (1928a) posiciona-se favorável ao que denominou de veículo de formação e afirma que não existia na Bahia uma escola a ser tomada como modelo, que se tornasse um local de visitação e observação por parte dos professores em trabalho e onde os normalistas pudessem praticar os modernos processos de ensino.

Desse modo, além de instituírem uma cultura de ensino e aprendizagem, os cursos de férias promoveram a atualização dos professores em conformidade com as novas exigências da sociedade e das ideias pedagógicas vigentes, cuja renovação imprescindível do ensino, deles dependia em grande parte.

\section{A didatização alvitrada pelos experts. indicativos para compreensão de uma aritmética para ensinar proposta na Bahia}

Anísio Teixeira constituiu-se em um expert em assuntos educacionais, mas não dominava as didáticas próprias de todos os componentes curriculares. Desse modo, ao propor a formação continuada dos professores, por meio dos cursos de férias, montou uma equipe de educadores que pudesse tratar das questões específicas de cada disciplina, fazendo uma transposição das indicações gerais da pedagogia trazida pelo movimento da Escola Nova para uma didática das disciplinas que compunham o currículo.

Esses educadores eram, em sua maioria, professores das Escolas Normais e, portanto, pessoas já experientes na formação de professores. Entretanto, as ideias advindas dos teóricos da Escola Nova eram algo novo para muitos formadores, isso porque esses cursos situam-se em um período de transição entre o ensino ativo e a escola ativa, o ensino pela intuição e o ensino pela ação.

É nesse contexto que Anísio irá repetir o que ocorreu com ele ao assumir o cargo de diretor geral da instrução pública: apresenta aos professores conferencistas, teóricos da escola ativa e fornece alguns livros para dar sustentação à formação que seria oferecida aos professores primários.

Para tratar do ensino de matemática (aritmética, geometria, desenhos e trabalhos manuais), Anísio convidou três conferencistas: o professor Arthur Mendes de Aguiar discutiu o ensino de geometria; a professora Alzira Assis, tratou do ensino de desenho e de 
trabalhos manuais; por fim, a professora Júlia Leitão abordou o ensino de aritmética e geometria na escola primária.

Como nos interessa, nesse artigo, discutir a aritmética para ensinar, tomaremos como referência apenas as três palestras proferidas pela professora Julia Leitão ${ }^{7}$, convidada, pessoalmente, pelo diretor geral da instrução pública, o professor Anísio Teixeira, para ministrar a conferência "O ensino de matemática na escola primária". Para ela, esse convite constituiu-se em um incentivo poderoso à nobre classe do professorado primário, pois uma professora primária estar ao lado de mestres competentíssimos era, em seu julgamento, uma grande honra. Considerou ainda que o convite, por certo, tenha levado em consideração a sua aceitação por parte dos professores, a sua prática já um tanto longa no ensino, bem como a proximidade da sua linguagem a um público formado por colegas de mesma profissão. Além de tudo isso, observou que o motivo maior desse convite residia no fato de estar há 5 anos conduzindo alguns estudos da pedagogia junto às alunas do Educandário do Sagrado Coração de Jesus.

A professora Júlia esclarece que a opção pela matemática foi uma escolha pessoal, já que possuía uma grande afinidade com a disciplina devido à metodologia utilizada pelo seu antigo professor, Dr. Arthur Hermenegildo da Silva, bem como, aos estímulos por ele recebidos (LEITÃO, 1927).

Inferimos que a expertise desenvolvida pela professora Júlia Leitão advém de uma formação multifacetada, estando imbricadas as experiências escolares como aluna do professor Arthur Hermenegildo, sua prática pedagógica como docente e os incentivos e fornecimento de material de formação recebidos por Anísio Teixeira.

Sua palestra no Curso de Férias de 1927 foi subdividida em três partes que se complementam para tratar das orientações para o ensino de aritmética e geometria na escola primária baiana a partir dos pressupostos do ensino ativo preconizado na reforma em andamento no estado.

Na primeira palestra, faz uma abordagem mais geral sobre como deve ser o ensino de matemática, dando ênfase aos assuntos relacionados à aritmética. Na segunda, aprofunda questões sobre o ensino de aritmética e, na terceira, o ensino de geometria. Essas orientações deixam vestígios da aritmética e da geometria para ensinar apresentadas no Curso de Férias.

Poderíamos, ainda, categorizar essas três palestras em dois grandes eixos: sendo um voltado para orientações mais gerais sobre o ensino de aritmética e geometria e outro, relacionada às orientações mais pontuais para o ensino de alguns conteúdos dessas disciplinas, por meio do detalhamento de como eles deveriam ser abordados em sala de aula.

As conferências realizadas pelos diversos experts foram reunidas e publicadas em uma edição especial da "Revista do Ensino", no ano de 1927. Além disso, em virtude das repercussões positivas que teve, as palestras da professora Julia Leitão deram origem a alguns artigos, posteriormente divulgados em diferentes edições da "Revista Educação", uma publicação da Escola Normal de Caetité.

\footnotetext{
7 Julia Leitão era professora de Pedagogia, Psicologia Infantil e Didática no Colégio Sagrado Coração de Jesus, escola religiosa particular equiparada às Escolas Normais e destinada ao público feminino.
} 


\section{Métodos, expertises e saberes a ensinar: entrelaces necessários a uma aritmética para ensinar}

Leitão (1927) faz uma acirrada crítica aos modelos tradicionais de ensino, apontando que alguns professores utilizavam de uma metodologia muito pautada na memorização das regras e fórmulas. Por outro lado, evidencia existir uma diversificação metodológica no ensino da matemática, já que havia aqueles que trabalhavam a partir da compreensão e de um raciocínio menos engendrado pelas regras e fórmulas.

Não desconsidera a importância da memória no processo de aprendizagem, mas esclarece que o ensino não deve se dar por meio da repetição e dos castigos físicos, a exemplo do uso da palmatória, infligidos pelos professores que têm dificuldade de ensinar. Nesse aspecto, propõe que haja uma forma de ensino colaborativo entre professores e alunos, pois esta interação e colaboração favorece a ação, tornando o ensino interessante, agradável ao aluno e menos cansativo, inclusive para o próprio mestre que não precisará gritar nem aplicar castigos físicos para manter a disciplina.

Suas palavras, proferidas há quase um século, se mostram muito atuais. Levanta questões metodológicas e convida à reflexão sobre o papel da escola, trazendo elementos que permaneceram no discurso pedagógico dos séculos XX e XXI. Para ela, se os mestres compreendessem que não basta formar alunos, é preciso formar cidadãos, não basta formar para o presente, é necessário formar para o futuro, para família, para a sociedade, para a pátria, então a escola passaria a assumir seu verdadeiro papel de formar filhos, irmãos e parentes dignos de atuar na sociedade e no seio da família.

Nesse projeto de escola, por ela defendido, a função da instituição escolar vai muito além de ensinar as matérias de cada disciplina. O que está em pauta é a escola como instrumento essencial de formação de um cidadão capaz de atuar na sociedade, honesto e, acima de tudo, dotado de um civismo para com a pátria e de boas condutas diante de Deus. Em outras palavras, seu discurso sobre o papel da escola fundamenta-se no tripé: formação de um cidadão honesto e capaz de atuar na sociedade; que tem em mente os valores cívicos e que seja possuidor das virtudes religiosas (LEITÃO, 1927).

Nessa afirmativa, identificamos uma expertise considerada necessária ao professor de matemática, ou seja, há a indicação de uma habilidade que compõe a aritmética para ensinar: estabelecer as relações existentes entre os conteúdos escolares e a vida, em outros termos, tornar os alunos aptos a fazer usos dos saberes aritméticos na sua atuação em sociedade. Isso implica em dominar e ensinar, não somente os conteúdos, mas conhecer e mostrar os campos e situações em que é possível sua aplicação.

Sobre o papel do mestre, Leitão (1927) esclarece que sua função não é a de um mero transmissor de conhecimento. O professor deve ser um educador no verdadeiro sentido do termo. Isso significa evitar os métodos de ensino tradicional, pautados na simples reprodução e transmissão de conhecimento, em que o educando é passivo no ato de aprender e, simplesmente, recebe o conhecimento já produzido, prescrito pela escola e adaptado pelo mestre.

O oposto desse perfil de aluno é, justamente, o que os princípios do método ativo, defendidos na reforma do ensino baiano e nas palestras do Curso de Férias, alvitravam. 0 lema defendido era a educação pela ação.

Ao fazer referência ao Programa de Ensino adotado no estado, por meio da reforma do ensino, a professora Júlia Leitão chama atenção para as orientações dadas, nesse programa, no que concerne à metodologia a ser adotada no ensino de aritmética. Para ela, 
especialmente, no primeiro e no segundo ano do curso elementar, o ensino deveria ter um caráter prático e intuitivo. Indica como deveria ser o ensino dos números até 100 citando os trabalhos desenvolvidos por Maria Montessori, de modo especial, o seu material das contas (recurso que hoje conhecemos por Material Dourado) que contribuem para a compreensão do sistema de numeração e possibilita pautar o ensino por meio de uma atividade concreta.

Referindo-se a Montessori e seu material das contas, a professora Júlia afirma:

Nós podemos imitá-la, mesmo prescindindo do auxílio dos contadores mecânicos, reunamos caroços de milho, de feijão, de malungú ou sementes de outros vegetaes e demos, a cada um delles, valores convencionados - de unidade, de dezenas, de centenas, etc. (LEITÃO, 1927 p. 160).

Mesmo diante da escassez de materiais didáticos e na ausência do material das contas, Leitão (1927) apresenta uma possibilidade de material alternativo para o trabalho inicial com os números e defende que só após esse trabalho de compreensão da noção de grandeza, seria possível trabalhar as operações fundamentais. Nesse sentido, a orientação aos professores era que trabalhassem, inicialmente, com a compreensão do sistema de numeração, focalizando sua característica decimal e posicional por meio de materiais manipulativos. Somente depois, seriam introduzidas as operações fundamentais, que deveriam ser trabalhadas de forma prática.

Tanto nessas orientações quanto no Programa de Ensino da escola primária elementar, publicado em 1925, há a indicação de que o ensino de aritmética deveria ser concreto nos dois primeiros anos e prático nos dois últimos.

Com o intuito de aprofundar e exemplificar a aritmética para ensinar e o seu caráter concreto e prático, a professora Júlia Leitão expôs algumas lições práticas, buscando demonstrar como deveria ser o trabalho com essa disciplina. Para isso, utilizou os conteúdos da adição; subtração; multiplicação; divisão; números pares e ímpares; números primos e múltiplos; e os números fracionários.

Mediante a realização de vários exercícios com material concreto e de sua problematização, para que as crianças percebessem, de forma intuitiva, o significado e as propriedades da operação, o professor proporia atividades mais abstratas, como, por exemplo, o algoritmo sem o uso do material manipulativo.

De modo geral, havia uma ênfase na utilização do quadro negro em paralelo à realização das atividades concretas. À medida que tais atividades fossem sendo realizadas, o professor precisaria estar muito atento para introduzir aspectos novos, essenciais à sua sistematização. Nesse momento, poderiam ser apresentadas informações complementares como o emprego dos sinais das operações, as denominações pelas quais cada parte é conhecida, etc.

Compunha, ainda, a aritmética para ensinar as operações fundamentais, a capacidade do professor em formular problemas, cujos dados estivessem atrelados ao universo infantil, de modo especial, às brincadeiras conhecidas pelos alunos. Para Leitão (1927), problematizar essas situações adquiria salutar importância para o ensino de aritmética, pois, por meio do brincar, o uso da matemática passaria a ser percebido pelas crianças como algo interessante, prazeroso e necessário.

Nessa conjuntura, a aritmética para ensinar envolvia a expertise de apresentar os saberes a ensinar conexos à ludicidade, sendo necessário, portanto, conhecer uma pouco 
da psicologia infantil. Para atender a essa exigência, os currículos, tanto da Escola Normal, quanto da Escola Normal Superior, contemplavam a formação em psicologia infantil.

Outro saber necessário ao professor de aritmética era a expertise de conduzir as aulas de modo que o aluno fosse em todo tempo desafiado a raciocinar.

Mais do que no ensino de qualquer outra matéria no da Arithmetica deve o professor, incessantemente, por meio de repetidas e adequadas perguntas ao alumno fazel-o raciocinar, pois no estudo dessa disciplina responder é quase sempre deduzir e, portanto, raciocinar e o alumno aprendendo raciocinar na Arithmetica, raciocinará também quando estudar as outras disciplinas do programma e ainda quando se the antolharem as questões, por vezes, complicadíssimas da vida prática (LEITÃO, 1927 p. 198).

Observamos que o desenvolvimento do raciocínio era visto como um elemento importante da aritmética a ensinar e, ao mesmo tempo, parte de uma aritmética para ensinar, ou seja, na medida em que o professor elaborava as perguntas adequadas que possibilitavam ao aluno racionar, ele o fazia a partir de estratégias próprias, linhas de pensamento singulares em cada novo cenário que se abria na ação educativa. Além disso, coloca a aritmética como disciplina base para as outras áreas do conhecimento e como um importante veículo de aproximação entre escola e vida prática.

Em linhas gerais, a aritmética para ensinar constituía-se, dentre outras coisas, na expertise do professor no domínio dos conteúdos, dos métodos e dos recursos de ensino, mas principalmente, na capacidade de adaptá-los às diferentes demandas: série, localidade, condições econômicas, etc. Nesse sentido, a formação no curso de férias pautou-se pela discussão desses três elementos, buscando fornecer algumas diretrizes.

Sobre o método, Leitão (1927 p. 198) diz que ele "deve ser intuitivo no princípio do curso e prático durante todo ele". Entretanto, mesmo fornecendo algumas dicas pontuais, caberia ao professor buscar para cada conteúdo e série os caminhos que o tornariam intuitivo, concreto e/ou prático.

No que se refere à concretude do ensino, Leitão (1927) esclareceu que não se tratava apenas da utilização de recursos didáticos caros e elaborados industrialmente, como os contadores mecânicos que poucas escolas possuíam. Faziam-se necessárias adaptações que permitissem a utilização de materiais acessíveis a todas as escolas e a todos as crianças, a exemplo de canetas, lápis, carteiras, livros e todo tipo de grãos presentes no cotidiano dos alunos.

Sobre os conteúdos, assinalou que além de seus recursos e métodos, deveria ser objeto de reflexão do professor a sequência em que eles seriam ensinados. Para Leitão (1927), o ensino das operações fundamentais, por exemplo, só deveria ser ministrado após as crianças construírem a ideia de número, orientação que nos remete inferir se tratar do uso do método sintético.

Observamos que a linha mestra das orientações didáticas com vista à formação de uma aritmética para ensinar, enfatizava o ensino intuitivo e concreto como algo indispensável à construção das estruturas cognitivas mais complexas. Em outras palavras, o desenvolvimento da capacidade de abstração era entendido como fruto das práticas didáticas que levavam em conta um ensino pautado em situações práticas e objetos reais.

Entretanto, Leitão (1927) esclarece que o ensino concreto não deve perpassar todos os níveis escolares, pois deixaria de ser um recurso facilitador da aprendizagem. 
É preciso, porém, notar que o ensino inteiramente concreto em todos os seus graus, longe de facilitar educação mental a contraria: só se deve concretizal-o até o ponto preciso para que as creanças comprehendam, sem tal recurso, o que se lhes quer ensinar (LEITÃO, 1927, p. 202).

Assim, faz uma distinção entre concreto e prático e diz que, embora o primeiro não, necessariamente, deva estar presente em todas as etapas do ensino, é imprescindível que a aritmética seja prática em todas as séries, e completa:

[...] quando se ensinar, por exemplo, o systema métrico [...] é de toda conveniencia mostrar aos alumnos um metro, um litro, um grammo [...] fazel-os medir a sala de aula, as mesas, os bancos; pesar, havendo balança, os livros, as ardósias, as bolsas, etc. [...] seja sempre o alvo visado no ensino da Arithmetica tornal-o sempre prático, essencialmente pratico (LEITÃO, 1927, p. 202-203).

Reforçando a necessidade de um ensino contextualizado e prático, afirmou que "não é para que os meninos tenham boas notas na aula que nas escolas se ensina Arithmetica; é, sim, para que de futuro, no mundo, ella lhes sirva de auxiliar nas frequentes emergencias da vida" (LEITÃO, 1927, p. 203).

Entretanto, embora deva considerar o cotidiano, orienta que não deve se limitar a ele, pois é preciso ampliar os horizontes para situações que extrapolam as vivências imediatas dessas crianças, trazendo para a sala de aula os saberes aritméticos atrelados a aplicações nas diversas profissões.

Para Leitão (1927), até mesmo as pessoas analfabetas conseguem fazer, com certa ponderação, os cálculos mais elementares da aritmética, pois isso atende as necessidades mais básicas do convívio em sociedade. No entanto, a maioria das profissões precisaram fazer o uso desse cálculo de uma forma mais precisa e profunda e cabe à escola elementar a função de iniciar o aluno nesse tipo de vivência.

Nessa perspectiva, identificamos um grande desafio para os professores, já que imbricada nesta aritmética para ensinar verifica-se implícita a exigência de saberes específicos de diferentes profissões, ou seja, trata-se de desenvolver a expertise de incorporar aos saberes aritméticos a ensinar a sua aplicação às variadas áreas profissionais. Isso só é possível com conhecimentos mínimos dos usos que cada profissional faz dos saberes aritméticos.

Além disso, Leitão (1927, p. 200) acrescenta que, em conformidade com os pressupostos da moderna pedagogia ${ }^{8}$, o ensino de aritmética precisaria despertar a curiosidade e o interesse dos alunos.

[...] é preciso que o professor procure, imagine, invente problemas que despertando a curiosidade e o interesse das crianças, as tornem attentas e activas, fazendo-as descobrir por ellas próprias, tudo que puderem aprender sem o auxílio do mestre.

\footnotetext{
${ }^{8}$ A moderna pedagogia à qual a professora Júlia Leitão se refere, não significa uma referência à vaga pedagógica conhecida como Pedagogia Moderna. Diz respeito aos pressupostos metodológicos da Escola Nova defendidos na reforma do ensino baiano de 1925. Nessa perspectiva, é de fundamental importância que as crianças interajam com seu objeto de estudo e sejam ativas no processo de construção do seu conhecimento.
} 
Para tanto, assinala mais uma expertise necessária ao professor de aritmética: a capacidade de elaborar problemas que, aproveitando das vivências dos alunos, aproximam a escola da vida prática, de modo a tornar o ensino atraente.

A elaboração ou escolha dos problemas mais apropriados constituía elemento privilegiado do planejamento. "Isto faz parte do preparo diario do professor; é uma coisa de necessidade imprescindível, um dever indeclinavel de todo o mestre que se preze, por mais preparado que seja elle" (LEITÃO, 1927, p. 205).

A preocupação maior estava na seleção do conteúdo e na elaboração dos problemas que seriam propostos aos alunos e não na especificação de como seriam ensinados, haja vista, que as questões metodológicas deveriam estar incorporadas à práxis pedagógica. Assim, o planejamento deveria detalhar os saberes a ensinar e não o como ensinar.

Outra discussão presente nessa palestra, refere-se à importância dos aspectos relacionais e/ou motivacionais para o ensino de aritmética. Segundo Leitão (1927), existiam professores que, mediante as dificuldades encontradas pelos alunos para resolver os problemas propostos, em vez de assumir uma postura que os ajudasse a avançar, incentivando o seu progresso e apontando os avanços adquiridos, assumiam, ao contrário, uma postura que prejudicava o aprendizado, constrangia e desmotivava os alunos na sua busca pelo conhecimento. Segundo Leitão (1927, p. 208) muitos professores utilizavam-se de frases pouco lisonjeiras como: "[...] bem via eu que você não acertava, você parece maluco, a intelligência passou por longe de sua cabeça [...] você é idiota ou é estupido".

Essas posturas e falas por parte de alguns professores criavam uma pedagogia da culpa que, além de prejudicar o aprendizado, inibia o aluno a ir além. $O$ incentivo dado pelo professor, ao contrário, contribuiria para que o aluno conseguisse avançar. Se a criança sentisse dificuldades para encontrar a solução dos problemas, caberia ao professor, sem dar a solução, fornecer pistas que o auxiliassem a descobrir o caminho por si só. Leitão (1927) ressaltou que, na vida prática, o adulto não acha mestres ao seu lado como a criança encontra na escola, portanto, era preciso que ela fosse capaz de construir, com a ajuda do professor, procedimentos mentais que garantissem a sua autonomia na resolução dos problemas, não só escolares, mas também, os que enfrentariam no seu dia a dia.

Além dos problemas, os jogos eram vistos por Leitão (1927) como desencadeadores do interesse. Nesse aspecto, se constituíam em um recurso imprescindível ao ensino de aritmética, já que, por meio deles, os problemas se apresentavam às crianças de uma forma mais lúdica e atrativa, principalmente, nos primeiros anos de escolaridade. À vista disso, conhecer e utilizar os jogos como recursos didáticos compunham uma expertise essencial a uma aritmética para ensinar.

Identificamos, ainda, que a aritmética para ensinar, proposta por Leitão (1927) implicavam em algumas noções preliminares de mediação da aprendizagem pelo professor, cujo objetivo era que o aluno construísse, de forma intuitiva e prática, os conceitos aritméticos. Em outros termos, na constituição de uma aritmética para ensinar, acrescentase ao que já foi apresentado, o domínio das técnicas de mediação da aprendizagem.

Mais tarde essa mediação/facilitação vai encontrar em teórico como Jean Piaget (1999), dentre outros, às vezes com nomenclaturas diferentes, uma mesma concepção para a postura do professor em relação ao aluno, entendendo o papel do mestre como, essencialmente, o de estabelecer uma ponte entre o aluno e o saber.

Compreendemos assim, a aritmética para ensinar como fruto do entrelace entre aritmética a ensinar e saberes para ensinar. Coube ao professor, por exemplo, fornecer aos alunos os conceitos e definições quando a aritmética a ensinar era fruto de convenções e, 
portanto, não passíveis de deduções. Por outro lado, essa mesma aritmética a ensinar, apoiada nos saberes para ensinar, advindos do movimento da Escola Nova, constituiu-se a base para a construção de uma didática ativa da aritmética no trato dos saberes que poderiam ser deduzidos/construídos. Em outros termos, utilizando-se das contribuições pedagógicas da Escola Nova, a aritmética para ensinar foi se constituindo em âmbito de uma didática que tornasse o ensino de aritmética interessante, ativo, concreto e prático.

\section{Algumas considerações}

A partir das contribuições advindas de autores ligados à História Cultural como Roger Chartier e Michel De Certeau, por meio de conceitos como apropriação, representação e estratégias, identificamos como Anísio Teixeira e os experts, designados por ele para a formação dos professores, apropriaram-se dos referenciais teóricos da Escola Nova e da Pedagogia Moderna e as representações sobre o ensino de aritmética presentes em seus discursos. Foi possível perceber, ainda, como os Cursos de Férias foram pensados estrategicamente para inculcar os novos ideais reformistas. Em outras palavras, esses conceitos nos subsidiaram, na medida em que possibilitou refletir sobre a concepção de educação e, mais especificamente, os pontos de vistas dos experts a respeito da aritmética para ensinar. Os documentos analisados deixaram vestígios das apropriações e representações que Anísio Teixeira e os experts, escolhidos por ele, fizeram do ideário pedagógico da Pedagogia Moderna e da Escola Nova, bem como, sua transposição em âmbito de uma aritmética para ensinar.

Sob o amparo da Reforma da Instrução e do movimento pedagógico da Escola Nova, diferentes conteúdos, saberes pedagógicos, métodos e matérias de ensino articularam-se na formação do professor primário, dando origem a uma aritmética para ensinar na escola baiana.

Os Cursos de Férias constituíram-se em estratégias adotadas por Anísio para apresentar diretrizes que propunham o rompimento com as formas de ensino tradicional. Nesse novo modelo de escola, o cerne da aritmética para ensinar residia no ensino pela ação, sendo expertise necessária ao professor, criar meios para colocar a criança no centro do processo educativo, torná-la agente responsável pela construção do conhecimento, que deveria se dar sempre a partir de atividades práticas, que valorizassem as vivências e experiências dos próprios alunos.

A ênfase metodológica para o ensino de aritmética residia na experimentação, observação e manipulação de objetos concretos para um gradativo desenvolvimento das estruturas mentais da criança, com vista à abstração e à construção de conceitos mais complexos dos números e das operações.

De modo geral, conjecturamos que, à medida que os métodos de ensino, os conteúdos e as questões didáticas da aritmética eram estudados, ressignificados, apropriados e repassados aos professores pelos experts, institucionalizava-se uma aritmética para ensinar, cujo tripé consistia em que ela fosse: concreta, prática e/ou lúdica.

A concepção de ensino, trazida pela Reforma da Instrução Pública, se desdobrou em didáticas específicas graças à equipe de experts montada por Anísio. No caso da aritmética, coube à professora Julia Leitão fazer essa transposição.

Nesse movimento, a aritmética para ensinar era fruto da intersecção entre a aritmética a ensinar e os saberes para ensinar, advindos da pedagogia da Escola Nova, que 
despontava, e da Pedagogia Moderna, ainda muito presente nas discussões educacionais desse período. Complementavam esse conjunto de saberes, o conhecimento da psicologia, do universo infantil e da realidade local, na qual os alunos estavam inseridos, o domínio dos recursos didáticos da aritmética e a capacidade do professor em estabelecer as interconexões entre os saberes aritméticos escolares e as situações da vida prática onde eles eram necessários.

\section{Referências}

\section{Fontes primárias}

ALVES, Isaias. Educação e Saúde na Bahia na interventoria Landulfo Alves. (abril 1938-junho 1939). Bahia, Gráfica e Editora Ltda., 1939.

BAHIA (estado). Lei no 1846 de 14 de agosto de 1925. Leis do Estado da Bahia dos annos de 1924 e 1925. Bahia, Imprensa Official do Estado, 1925a.

LEITÃO, Julia. O ensino de matemática na escola primária. Revista do Ensino. Bahia Anno III (número especial) - Curso de Férias, Bahia, 1927.

TEIXEIRA, A. S. Relatório apresentado ao Ex. Sr. Cons. Bráulio Xavier da Silva Pereira. Secretário do Interior, Justiça e Instrução Pública pelo Diretor Geral da Instrução Pública, para ser encaminhado ao governador do Estado da Bahia. Salvador: Imprensa Oficial do Estado, 1928a. Disponível em: <http://www.bvanisioteixeira.ufba.br/>. Acesso em: 19 jun. 2016.

TEIXEIRA, A. S. Aspectos americanos de educação. Salvador: Tip. De São Francisco, 1928b. 166p. Disponível em: < http://www.bvanisioteixeira.ufba.br/artigos/aspamerieducacao/indice.htm>. Acesso em: 19 jun. 2016

\section{Fontes secundárias}

BLOCH, Marc. Apologia da História ou o ofício de Historiador, Rio de Janeiro: Jorge Zahar Editor, 2001.

BOMENY, H. Os intelectuais da educação. 2 ed. Rio de Janeiro: Jorge Zahar, 2003.

CHARTIER, Roger. A história cultural: entre práticas e representações. Editora Bertrand Brasil. Rio de Janeiro, 1990.

CHARTIER, Roger. À Beira da Falésia: a história entre incertezas e inquietude. Porto Alegre: Ed. Universidade/UFRGS, 2002.

DE CERTEAU, Michel. A invenção do cotidiano: 1. Artes de fazer. Petrópolis, Rio de janeiro: Vozes, 1994.

D’ESQUIVEL, Márcio Oliveira. O ensino de Desenho e Geometria para a escola primária na Bahia (1835-1925). 121f. Dissertação (Mestrado) - Universidade Estadual do Sudoeste da Bahia, Jequié, BA, 2015.

DUBREUCQ, Francine. Jean-Ovide Decroly. Recife: Editora Massangana, 2010. 
FARIA FILHO, L. M; VIDAL, Diana. Os tempos e os espaços escolares no processo de institucionalização primária no Brasil. Revista Brasileira de Educação, São Paulo n.14, p. 1934, mai./ago.2000

HEILAND, Helmut. Friedrich Fröbel/Helmut Heiland; tradução: Ivanise Monfredini. Recife: Fundação Joaquim Nabuco, Editora Massangana, 2010.

HOFSTETTER, Rita; SCHNEUWLY, Bernard; FREYMOND, Mathilde de. Penetrar na verdade da escola para ter elementos concretos de sua avaliação: a irresistível institucionalização do expert em educação (século XIX e XX). In: HOFSTETTER, Rita; VALENTE, Wagner Rodrigues (Orgs.). Saberes em (trans)formação: tema central da formação de professores. São Paulo: Editora Livraria da Física, 2017

KISHIMOTO, Tizuko Morchida. Froebel e a concepção de jogo infantil. Revista da Faculdade de Educação, [S.I.], v. 22, n. 1, p. 145-167, jan. 1996. ISSN 1806-9274. Disponível em: <http://www.revistas.usp.br/rfe/article/view/33600>. Acesso em: 24 maio 2017.

PIAGET, J. Seis estudos de psicologia. Trad. Maria A.M. D'Amorim; Paulo S.L. Silva. 24 ed. Rio de Janeiro: Forense, 1999.

SANT'ANA, Claudinei de Camargo et al. A constituição dos saberes matemáticos na escola primária do estado da Bahia, século XIX-XX. In: SEMINÁRIO TEMÁTICO: O ENSINO DA MATEMÁTICA NA ESCOLA PRIMÁRIA (XIX - XX) - ENCONTRO FRANCO-BRASILEIRO, 13, 2015, Limoges - França. Anais do Seminário Temático. Disponível em: < http://seminariotematicofrancobrasileiro. $\quad$ paginas.ufsc.br/files/2015/ 12/ACONSTITUI\%C3\%87\%C3\%83O-DOS-SABERES-MATEM\%C3\%81TICOS-NA-SCOLA-

PRIM\%C3\%81RIA-DO-ESTADO-DA-BAHIA-SECULO-XIX-XX.pdf>. Acesso em: 16 de junho de 2016.

VALENTE, Wagner Rodrigues. A Matemática a ensinar e a Matemática para ensinar: os saberes para a formação do educador matemático. In: HOFSTETTER, Rita; VALENTE, Wagner Rodriges (Orgs.). Saberes em (trans)formação: tema central da formação de professores. São Paulo: Editora Livraria da Física, 2017 